\title{
Estimating the Proportional Contributions of Multiple Nitrate Sources in Shallow Groundwater with a Bayesian Isotope Mixing Model
}

\author{
Wen Xu, Yanpeng Cai, Qian Tan, and Yan Xu
}

\begin{abstract}
In this study, a dual stable isotope approach and a Bayesian isotope mixing model (SIAR model) were applied to estimate the proportional contributions of multiple $\mathrm{NO}_{3}^{-}$sources to shallow groundwater. The concentration of groundwater $\mathrm{NO}_{3}{ }^{-}$ranged widely from 5.7 to $26.2 \mathrm{mg} / \mathrm{L}$, with the $\delta^{15} \mathrm{~N}$ values changed from 7.1 to $11.3 \%$ and the $\delta^{18} \mathrm{O}$ values varied from 5.4 to $11.6 \%$. According to the classical dual isotope bi-plot, manure and sewage (M\&S), soil $\mathrm{N}$ (Soil), $\mathrm{NO}_{3}{ }^{-}$in chemical fertilizer (NF) $\mathrm{NH}_{4}{ }^{+}$in chemical fertilizer and precipitation (NP) were identified as the four potential $\mathrm{NO}_{3}{ }^{-}$sources to groundwater. And the outputs of SIAR model showed some variability in the contribution of each $\mathrm{NO}_{3}{ }^{-}$source. "Soil" contributed the most (between $21 \%$ and 70\%), followed by "NF" (between15\% and 45\%), "M\&S" (between 4\% and 39\%), "NP" (between $0 \%$ and $20 \%$ ). The SIAR model showed be considered as a reliable approach to quantify the proportional contributions of multiple $\mathrm{NO}_{3}{ }^{-}$sources in the mixture.
\end{abstract}

Index Terms-Dual stable isotopes, shallow groundwater, proportional contributions of $\mathrm{NO}_{3}{ }^{-}$sources, SIAR model.

\section{INTRODUCTION}

Nitrate $\left(\mathrm{NO}_{3}{ }^{-}\right)$contamination of water is a prominent environmental problem worldwide. With the increasing of human disturbance, the natural nitrogen $(\mathrm{N})$ cycle has been extensively altered, doubling the rate of $\mathrm{N}$ inputs into the terrestrial $\mathrm{N}$ cycles [1], [2]. A considerable mass of reactive nitrate may accumulate in the unsaturated zone (UZ) by anthropogenic activities involving $\mathrm{N}$ compounds (e.g., the liberal application of $\mathrm{N}$ fertilizers) and byproducts of organic matter from agriculture, septic system, animal manure et al. [3]-[6].

Groundwater is an important source of water supply for both municipal and industrial use in many regions [7]. The quality of groundwater is susceptible to the mobilization of reactive nitrate by activities (e.g., irrigation, sewage disposal and rainfall penetration) that enhance infiltration to the UZ [8], [9], thus accelerating the leaching of nitrate into groundwater. High concentrations of nitrate in groundwater not only potentially threaten the aquatic ecosystem, but also pose great risks to human health [6], [10]-[12]. Therefore, the World Health Organization has set a limit of $10 \mathrm{mg} / \mathrm{L}$ NO3--N for

Manuscript received May 18, 2015; revised September 17, 2015 This work was supported in part by the School of Environment, Beijing Normal University, China.

Wen $\mathrm{Xu}$, Yanpeng Cai, and Yan Xu are with the School of Environment, Beijing Normal University, China (e-mail: xuwen8971@163.com, yanpeng.cai@bnu.edu.cn).

Qian Tan is with the Institute for Energy, Environment and Sustainable Communities, University of Regina, Canada. drinking water [11].

In general, groundwater has limited capacity for cleansing nitrate through natural process (e.g., dilution, denitrification et al.) and the hydrology conditions of groundwater aquifers are sophisticated. Therefore, the remediation of polluted groundwater would be costly with lots of uncertainties [13] The most fundamental approach to deal with groundwater nitrate contamination is to find the source of nitrate and cut it off [14]. Hence, tracking the sources of nitrate in groundwater is of great significances to improve groundwater quality and manage human activities. Sources of nitrate in water are of great diversity. While it's feasible to deduce these origins by traditional hydrochemical methods, such as the analysis of $\mathrm{NO}_{3}{ }^{-}$mass concentration and/or the concentration features of some other ions in combination with land use patterns and tillage practices [15]-[18]. However, using hydrochemical methods alone may just provide indirect evidences for nitrate sources extrapolation, and the results are uncertain in some extend. With the advancing of isotope probing, researchers discovered that different NO3- sources have distinct isotopic ratios of both $\delta 15 \mathrm{~N}$ and $\delta 18 \mathrm{O}$. The typical domain of $\delta 15 \mathrm{~N}$ and $\delta 18 \mathrm{O}$ values of different nitrate sources was concluded by Kendall et al. through extensive statistical analysis [19]. Afterwards, a dual isotope approach $\left(\delta^{15} \mathrm{~N}\right.$ and $\delta^{18} \mathrm{O}$ in $\left.\mathrm{NO}_{3}{ }^{-}\right)$ to identify nitrate sources in surface or subsurface water was booming. Fatima et al. successfully used $\delta^{15} \mathrm{~N}$ and $\delta^{18} \mathrm{O}$ to identify agriculture effluents and wastewater as two main sources of $\mathrm{NO}_{3}^{-}$in springs of a human-impacted catchment [20]. Zhang et al. combined the $15 \mathrm{~N}$ and $18 \mathrm{O}$ isotopes to trace the derivation of groundwater $\mathrm{NO} 3$ - in sewage irrigation areas and undisturbed regions comparatively. Data indicated that wastewater and soil mineralized nitrogen were the dominant origin of groundwater nitrate in these two sites respectively [21].

Some researchers also applied $\delta^{15} \mathrm{~N}$ and $\delta^{18} \mathrm{O}$ to quantify the proportional contributions of multiple nitrate sources to aquatic environment via the mass balance model [22], [23]. However, the mass balance model became deficient in drawing accurate conclusions when more than three nitrate sources existed in water simultaneously [19]. And the model itself had numerous uncertainties as well [24], [25]. Plenty of approaches to revise the mass balance model have been proposed [26]-[28]. Among which Andrew et al. provided a novel insight in partitioning multiple sources in the mixture. They established a SIAR (Stable Isotope Analysis in R) model, which was designed for food-web analysis primitively. The SIAR model uses a Bayesian framework to determine the possible proportional source contribution and the distribution of each source's contribution to the mixture [28], [29]. Since 
the SIAR model could incorporate three vital uncertainties in quantifying the proportional contributions of multiple nitrate sources, such as 1) temporal and spatial variance of $\delta^{15} \mathrm{~N}$ and $\delta^{18} \mathrm{O}$ in $\left.\mathrm{NO}_{3}{ }^{-} ; 2\right)$ isotopic fractionations during denitrification; (3) too many $\mathrm{NO}_{3}{ }^{-}$sources (number of sources $>$number of isotopes + 1) [24]. Many researchers attempted to identify the multiple nitrate sources as well as quantifying their proportional contributions via the SIAR model, and the results were inspiring. Xue et al. applied the SIAR model to fingerprint the contribution of potential $\mathrm{NO}_{3}^{-}$sources in agriculture affected surface water. The output showed that the biggest and the least contributors were "manure and sewage" and " $\mathrm{NO}_{3}{ }^{-}$in precipitation" respectively [30]. Marion et al. estimated the inputs of two nitrate sources (sewage and atmospheric deposition) concentrated in urban watersheds with SIAR model. Results indicated that sewage was the dominant source despite the spatial and temporal variety. Up to $94 \%$ and $66 \%$ of nitrate originated from sewage during base flow and storm flow respectively. While atmospheric deposition merely became a substantial nitrate source under storm conditions, with a proportional contribution being no more than $36 \%$ [31]. However, the SIAR model has not yet been prevalently applied to identify and quantify nitrate sources in groundwater, which is also susceptible to human activity and plays significant roles as well as surface water does.

The purpose of this study was to estimate the proportional contributions of the potential nitrate sources in groundwater of an urbanized watershed. Firstly, a dual stable isotope approach $\left(\delta^{15} \mathrm{~N}\right.$ and $\delta^{18} \mathrm{O}$ in $\left.\mathrm{NO}_{3}{ }^{-}\right)$was adopted to identify the main origins of groundwater nitrate. Afterwards, the SIAR model was operated to output the distribution of each nitrate source's relative contribution to the mixture. Finally, an analysis that combined nitrate sources with hydrology conditions as well as human disturbances was made, based on which advices on improving groundwater quality could be proposed.

\section{MATERIALS AND METHODS}

\section{A. Site Description}

Shijiazhuang city is situated in the south central of Hebei province, with an urban area of about $455.81 \mathrm{~km}^{2}$ and a good reputation of "the northern granary" in China. The physiognomy of the region is flat with a slight gradient of $1.6 \sim 2.5$ to $0.5 \sim 1.0 \%$ from the west to the east. The city has a semi-arid and semi-humid continental monsoon climate, and the precipitation period is between June to September. Hutuohe was the biggest river of the city, however, since the Huangbizhuang reservoir being constructed in the upper stream, Hutuohe has became a seasonal river.

The main strata of this region belongs to the Quaternary deposit, of which the lithology includes medium coarse sand, intermediate fine sand and cohesive soil. The relatively water-enriched formation for phreatic water is the shallow groundwater aquifer. The bottom depth of shallow groundwater aquifer increases eastward from $20 \mathrm{~m}$ to $200 \mathrm{~m}$ gradually, while the granularity of the aquifer changes in the opposite way. The hydrochemical types of shallow groundwater were $\mathrm{HCO}_{3}-\mathrm{Ca}, \mathrm{HCO}_{3}-\mathrm{Ca} \cdot \mathrm{Mg}$ in the west, and $\mathrm{HCO}_{3}-\mathrm{Na}, \mathrm{HCO}_{3}-\mathrm{Ca} \cdot \mathrm{Mg}, \mathrm{SO}_{4}-\mathrm{Na}$ and $\mathrm{SO}_{4}-\mathrm{Mg}$ in the east. Since the 1950s, groundwater especially shallow groundwater in this city has been intensively exploited for domestic, industrial and agriculture use. With the aggravation of human disturbance, shallow groundwater has been seriously contaminated, and the water quality has been continuously degraded, such as the elevation of $\mathrm{NO}_{3}{ }^{-}$concentration from $4.38 \mathrm{mg} / \mathrm{L}$ in 1959 to $54.07 \mathrm{mg} / \mathrm{L}$ in 2000 [32]

\section{B. Groundwater Sampling and Analysis}

About 13 shallow groundwater samples were collected from domestic wells or agricultural motor-pumped wells in September, 2011. These wells were distributed from Yancun to Gaoqianbeijie, along with the groundwater flow approximately. Five liters of fresh water was collected in each site for $\mathrm{NO}_{3}^{-}$concentration analysis and ${ }^{15} \mathrm{~N},{ }^{18} \mathrm{O}$ isotope analysis.

The concentration of $\mathrm{NO}_{3}^{-}$was determined by the ion-chromatographic analyzer, with a $0.001 \mathrm{mg} / \mathrm{L}$ test precision.

${ }^{15} \mathrm{~N}$ and ${ }^{18} \mathrm{O}$ isotopes were measured by the isotope ratio mass spectrometer with high-temperature pyrolysis method. The compositions of ${ }^{15} \mathrm{~N}$ and ${ }^{18} \mathrm{O}$ was expressed in per mil (\%o) relative to the corresponding international standard:

$$
\delta_{\text {sample }}(\%)=\left(\frac{\delta_{\text {samples }}-\delta_{\text {standard }}}{\delta_{\text {standard }}}\right) \times 1000
$$

where the standards for ${ }^{15} \mathrm{~N}$ and ${ }^{18} \mathrm{O}$ values are $\mathrm{N}_{2}$ in atmosphere (AIR) and Vienna Standard Mean Ocean Water (VSMOW) respectively.

The result of hydro-chemical and isotopic analysis of all the samples is referred to the following Table I.

TABLE I: $\mathrm{NO}_{3}{ }^{-}$CONCENTRATION AND THE ISOTOPIC COMPOSITIONS

\begin{tabular}{|c|c|c|c|}
\hline Sample site & $\mathrm{NO}_{3}^{-}(\mathrm{mg} / \mathrm{L})$ & $\delta^{15} \mathrm{~N}_{\mathrm{NO} 3}(\%)$ & $\delta^{18} \mathrm{O}_{\mathrm{NO} 3}(\%)$ \\
\hline Yancun & 10.7 & 7.8 & 10.3 \\
\hline Baichigan & 13.3 & 7.8 & 6.2 \\
\hline Dahe & 21.4 & 8.0 & 8.6 \\
\hline Houduibei & 6.5 & 9.5 & 9.6 \\
\hline Shiqiyu & 16.2 & 7.1 & 7.7 \\
\hline Taitou & 15.6 & 11.1 & 11.6 \\
\hline Beigaoying & 26.2 & 8.2 & 5.6 \\
\hline Xiguan & 22.3 & 7.2 & 5.4 \\
\hline Taipingcun & 17.3 & 9.3 & 6.7 \\
\hline Bafang & 5.7 & 9.1 & 11.5 \\
\hline Dongxuying & 7.7 & 10.1 & 9.6 \\
\hline Shaojiazhuang & 23.2 & 8.2 & 9.1 \\
\hline Gaoqianbeijie & 15.1 & 11.3 & 7.4 \\
\hline
\end{tabular}

\section{SIAR Mixing Model}

The model of SIAR is formulated as follows [29]:

$$
\left\{\begin{aligned}
x_{i j} & =\sum_{k=1}^{K} p_{k}\left(s_{j k}+c_{j k}\right)+\varepsilon_{i j} \\
s_{j k} & \sim N\left(\mu_{j k}, \omega_{j k}^{2}\right) \\
c_{j k} & \sim N\left(\lambda_{j k}, \tau_{j k}^{2}\right) \\
\varepsilon_{i j} & \sim N\left(0, \sigma_{j}^{2}\right)
\end{aligned}\right.
$$

where $x_{i j}$ is the isotope value $j$ of the mixture $i ; p_{k}$ is the 
proportional contribution of source $\mathrm{k} ; s_{j k}$ is the source value $k$ on isotope $j ; \mu_{j k}$ and $\omega_{j k}$ are mean value and standard deviation of the distribution of $s_{j k}$ respectively; $c_{j k}$ is the fractionation factor for isotope $\mathrm{j}$ on source $\mathrm{k} ; \lambda_{j k}$ and $\tau_{j k}$ are mean value and standard deviation of the distribution of $c_{j k}$ respectively; $\varepsilon_{i j}$ is the residual error representing the additional variation between individual mixtures that hasn't been quantified; $\sigma_{j}$ is the standard deviation of the distribution of $\varepsilon_{i j}$; in which $i, j, k$ are positive integers.

\section{RESULTS AND DISCUSSION}

\section{A. Spatial Variance of Groundwater $\mathrm{NO}_{3}{ }^{-}$Concentrations}

According to the result shown in Table I, the concentration of groundwater $\mathrm{NO}_{3}{ }^{-}$ranged widely from 5.7 to $26.2 \mathrm{mg} / \mathrm{L}$, with an average value of $15.5 \mathrm{mg} / \mathrm{L}$ (Fig. 1). Specifically, about half of the groundwater samples had fluctuant $\mathrm{NO}_{3}{ }^{-}$ concentrations around the average value. While the rest samples showed anomalous concentration of $\mathrm{NO}_{3}{ }^{-}$more or less, which might be the result of hydro-geochemical process, human disturbance, or the integration of both.

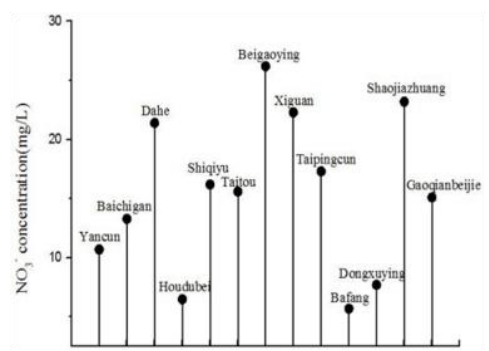

Fig. 1. Spatial distribution of $\mathrm{NO}_{3}{ }^{-}$concentration in shallow groundwater.

Sampling sites such as Houdubei, Bafang and Dongxuying had abnormally low groundwater $\mathrm{NO}_{3}^{-}$concentrations. Houdubei was in the neighborhood of Huangbizhuang reservoir, which was the most important and favorable source of drinking water to Shijiazhuang city, with a very low $\mathrm{NO}_{3}$ concentration of merely $2.63 \mathrm{mg} / \mathrm{L}$. According to the hydrology conditions, Huangbizhuang reservoir was likely to recharge the groundwater adjacently. Meanwhile, the condition of water circulation was much better in places near the reservoir. Therefore, the concentration of groundwater $\mathrm{NO}_{3}{ }^{-}$in Houdubei was relatively lower. However, Bafang and Dongxuying had comparatively low groundwater $\mathrm{NO}_{3}{ }^{-}$ concentrations as well, though the two sampling sites were neither near the Huangbizhuang reservoir nor had good hydraulic conditions. There might be three main reasons for this phenomenon. Firstly, the number of aquifer layers was increasing with the size of aquiferous medium being decreased. Therefore, aquifers in such area had low permeability that pollutants (e.g., $\mathrm{NO}_{3}{ }^{-}$) could be prevented from entering groundwater in large extent. Secondly, both sealed aquifer conditions and long hydraulic retention time were favorable for some certain microbial activities, such as the denitrification, by which groundwater $\mathrm{NO}_{3}{ }^{-}$concentration could be reduced greatly. So far, denitrification has been proved to exist in groundwater environment and applied to the in situ remediation of groundwater contamination [33], [34]. Presently we are working on the microbial denitrification in groundwater of the studied area. Thirdly, according to our field survey, groundwater in these three sampling sites were mainly for drinking use. And the wells were situated within the house yards that were relatively far from farmlands and had large impervious surface, thus reducing the possibility of groundwater being polluted by fertilizer $\mathrm{N}$ residues and soil $\mathrm{N}$ leaching.

Conversely, sampling sites such as Dahe, Beigaoying, Xiguan and Shaojiazhuang had abnormally high groundwater $\mathrm{NO}_{3}{ }^{-}$concentrations. Dahe, Beigaoying and Xiguan were situated in the neighborhood of two eutrophicated surface waters (e.g., Shijin canal and Hutuo river). According to the hydrological conditions, groundwater aquifers of these sampling sites had relatively good permeability, thus providing favorable conditions that groundwater being recharged by the eutrophicated surface waters. Shaojiazhuang was in the south of Shijiazhuang city, where sewage irrigation has been widely applied since the 1950s. Due to the high concentration of $\mathrm{NO}_{3}^{-}$in sewage water generally, groundwater in this region might show more enrichment in $\mathrm{NO}_{3}{ }^{-}$than the rest regions. Additionally, based on our field survey, the sampling well in Shaojiazhuang was an agricultural motor-pumped well that located within the cropland. Hence, chemical fertilizers, animal manures and soil $\mathrm{N}$ might become potential contributors to the accumulation of shallow groundwater $\mathrm{NO}_{3}{ }^{-}$. Specifically, we have conducted an experiment of groundwater E. coli bacteria cultivation. The result showed that after a 24 hours' incubation, the number of E. coli bacteria flora in groundwater of Shaojiazhuang sample site was more than 200. And the enrichment of E. coli bacteria was a valid implication of sewage and manure migrated into the groundwater.

\section{B. Identify Potential $\mathrm{NO}_{3}{ }^{-}$Sources to Groundwater Using} Dual Stable Isotopes

The $\delta^{15} \mathrm{~N}$ and $\delta^{18} \mathrm{O}$ values of all the groundwater samples can be seen in Table I. The value of $\delta^{15} \mathrm{~N}$ ranged from 7.1 to $11.3 \%$, and the mean value was $8.8 \%$. The $\delta^{15} \mathrm{~N}$ values of shallow groundwater in the studied area showed good consistent with the $\delta^{15} \mathrm{~N}$ values in reported agricultural areas (e.g., 2.7-14.6\%o and 8.2-11.3\%o) [35], [36]. Sampling sites such as Taitou and Gaoqianbeijie showed relatively higher $\delta^{15} \mathrm{~N}$ values, which were 11.1 and $11.3 \%$ respectively. While sampling sites such as Shiqiyu and Xiguan showed relatively lower $\delta^{15} \mathrm{~N}$ values, which were 7.1 and 7.2\% respectively.

The value of $\delta^{18} \mathrm{O}$ ranged from 5.4 to $11.6 \%$, and the mean value was $8.4 \%$. The $\delta^{18} \mathrm{O}$ values were the highest in sampling sites such as Bafang and Taitou, from 11.5 to $11.6 \%$. While the lowest $\delta^{18} \mathrm{O}$ values were in sampling sites such as Xiguan and Beigaoying, from 5.4 to $5.6 \%$.

On the whole, the composition of ${ }^{15} \mathrm{~N}$ and ${ }^{18} \mathrm{O}$ isotopes showed distinct heterogeneity in spatial distribution, which was an implication of diversified nitrate sources to shallow groundwater. In this study, the method of classical dual isotope bi-plot was chosen to identify potential $\mathrm{NO}_{3}{ }^{-}$sources to the shallow groundwater (Fig. 2).

It was obvious that isotopic composition of groundwater 
samples mainly fell into the range of "manure and sewage" and "soil $\mathrm{N}$ " sources, and few were on the edge of " $\mathrm{NO}_{3}{ }^{-}$in chemical fertilizer" and " $\mathrm{NH}_{4}{ }^{+}$in chemical fertilizer and precipitation" source windows as well. However, none sample showed similar isotopic composition to the source of

" $\mathrm{NO}_{3}{ }^{-}$in precipitation" (Fig. 2). As a whole, the distribution of groundwater isotopic composition in this bi-plot indicated four kinds of potential $\mathrm{NO}_{3}{ }^{-}$sources to groundwater, including manure and sewage (M\&S), soil $\mathrm{N}$ (Soil), $\mathrm{NO}_{3}{ }^{-}$in chemical fertilizer (NF), $\mathrm{NH}_{4}{ }^{+}$in chemical fertilizer and precipitation (NP) respectively. Meanwhile, the largest contributor of groundwater $\mathrm{NO}_{3}{ }^{-}$would be manure and sewage, followed by soil $\mathrm{N}$. While $\mathrm{NO}_{3}{ }^{-}$in chemical fertilizer or $\mathrm{NH}_{4}{ }^{+}$in chemical fertilizer and precipitation would make the least contribution to groundwater $\mathrm{NO}_{3}{ }^{-}$.

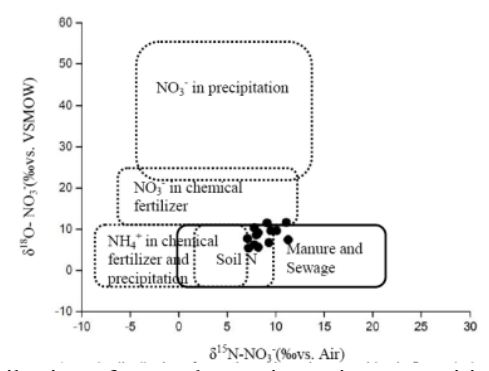

Fig. 2. The distribution of groundwater isotopic composition in five typical $\mathrm{NO}_{3}{ }^{-}$sources.

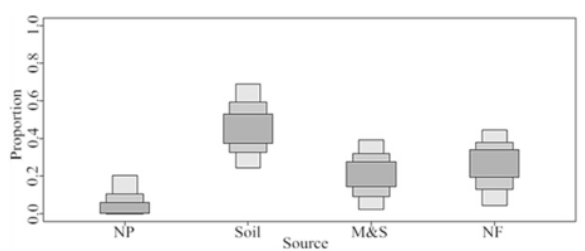

Fig. 3. Box plot of potential $\mathrm{NO}_{3}$-sources proportion.

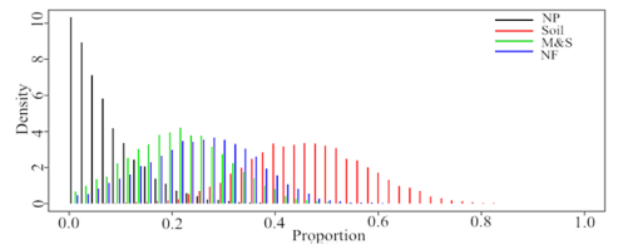

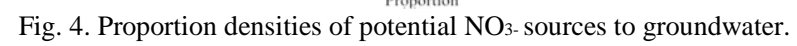

However, the classical dual isotope bi-plot approach merely output rough results of potential $\mathrm{NO}_{3}{ }^{-}$sources, while could not give conclusive information regarding the proportional contributions of all the potential $\mathrm{NO}_{3}{ }^{-}$sources. Therefore, a more quantitative method need to be adopted.

\section{Quantify the Proportional Contributions of $\mathrm{NO}_{3}$ Sources with SIAR Model}

In order to estimate the proportional contributions of the four potential $\mathrm{NO}_{3}{ }^{-}$sources (e.g., M\&S, Soil, NF and NP) deduced from the classical bi-plot (Fig. 2), a SIAR model was applied. And the model outputs showed certain variability among the contributions of the four potential $\mathrm{NO}_{3}{ }^{-}$sources.

The range of each $\mathrm{NO}_{3}{ }^{-}$source's contribution was shown in the box plot (Fig. 3). And the mean probability estimate (MPE) of proportion density of four potential $\mathrm{NO}_{3}{ }^{-}$sources were normally distributed (Fig. 4). Specifically, the contribution of "Soil" was the highest (between $21 \%$ and $70 \%$ ), followed by "NF" (between $15 \%$ and 45\%), "M\&S" (between 4\% and $39 \%$ ), "NP" (between $0 \%$ and 20\%).
The quantitative outputs by SIAR model (Fig. 3) showed good consistent with the approximate analysis results from classical bi-plot (Fig. 2). In general, "Soil" contributed the most, which indicated a high background value of soil $\mathrm{NO}_{3}{ }^{-}$. Besides, the groundwater samples were collected in September, during which temperature and moisture of the soil were favorable for microbial activities (e.g., the transformation of soil organic $\mathrm{N}$ into $\mathrm{NH}_{4}^{+}$and/or $\mathrm{NO}_{3}{ }^{-}$). "NF" and "M\&S" contributed intermediate, and main reason was that some of the groundwater samples were collected from wells located in or near the farmlands. Therefore, $\mathrm{NO}_{3}$ concentrations of shallow groundwater in these locations were susceptible to agricultural activities such as chemical fertilizer and/or animal manure application, sewage irrigation. "NP" contributed the least, possible interpretation might be that rainfall in this area had relatively low $\mathrm{NH}_{4}{ }^{+}$concentration. Besides, during the week we collected groundwater samples, no significant precipitation has happened, thus little $\mathrm{NH}_{4}{ }^{+}$was permeated into groundwater and oxidized into $\mathrm{NH}_{4}{ }^{+}$.

\section{CONCLUSION}

Presently, although the concentration of $\mathrm{NO}_{3}{ }^{-}$in shallow groundwater haven't reached or exceeded the limit set by the World Health Organization, human disturbance was confirmed to be one of the dominant factors leading to the enrichment of $\mathrm{NO}_{3}{ }^{-}$in groundwater. Our study showed that manure and sewage $(\mathrm{M} \& \mathrm{~S})$, soil $\mathrm{N}$ (Soil), $\mathrm{NO}_{3}{ }^{-}$in chemical fertilizer (NF) and $\mathrm{NH}_{4}^{+}$in chemical fertilizer and precipitation (NP) were the four potential $\mathrm{NO}_{3}{ }^{-}$sources to groundwater. And the SIAR model was applied to estimate the proportional contributions of each $\mathrm{NO}_{3}^{-}$source. The output of SIAR model showed some variability in the distribution of the four potential $\mathrm{NO}_{3}{ }^{-}$sources' contribution. The contribution of "Soil" was the highest (between $21 \%$ and $70 \%$ ), followed by "NF" (between $15 \%$ and 45\%), "M\&S" (between 4\% and 39\%), "NP" (between $0 \%$ and 20\%). The variability was the result of human activity, sampling well location, as well as the hydro-meteorology. The SIAR model is a reliable approach to quantify the proportional contributions of multiple $\mathrm{NO}_{3}{ }^{-}$sources in the mixture, and should be considered as the fingerprint of potential $\mathrm{NO}_{3}$ sources.

\section{ACKNOWLEDGMENT}

This study has been supported by the National Science Foundation for Innovative Research Group (No. 51121003), and the Fundamental Research Funds for the Central Universities (2014KJJCB10).

\section{REFERENCES}

[1] P. M. Vitousek, J. D. Aber, and R. W. Howarth, "Human alteration of the global nitrogen cycles: Sources and consequences," Ecological Applications, vol. 4, pp. 737-750, 1997.

[2] R. Howarth, "Human acceleration of the nitrogen cycle: Drivers, consequences, and steps toward solutions," Water Science and Technology, vol. 49, pp. 7-13, 2004.

[3] A. E. Williams, L. J. Lund, and J. A. Johnson, "Natural and anthropogenic nitrate contamination of groundwater in a rural community, California," Environmental Science and Technology, vol. 32, pp. 32-39, 1998.

[4] W. David, P. G. Emmanuelle, and N. Philippe, "Tracking the sources of nitrate in groundwater using coupled nitrogen and boron isotopes: A 
synthesis," Environmental Science and Technology, vol. 39, pp. $539-548,2005$

[5] J. H. Zhang, J. L. Liu, and J. B. Zhang, "Nitrate-nitrogen dynamics and nitrogen budgets in rice-wheat rotations in Taihu Lake region," China Pedosphere, vol. 23, no. 1, pp. 59-69, 2013.

[6] J. T. Ding, B. D. Xi, and R. T. Gao, "Identifying diffuse nitrate sources in a stream in an agricultural field using a dual isotopic approach," Science of the Total Environment, vol. 484, pp. 10-18, 2014.

[7] J. S. William, G. Bernard, and M. Timothy, "Nitrate contamination in groundwater an urbanized dairy farm," Environmental Science and Technology, vol. 42, pp. 4683-4688, 2008.

[8] J. S. Michael, N. W. Katharine, and E. C. Mark, "Tracking sources of unsaturated zone and groundwater nitrate contamination using nitrogen and oxygen stable isotopes at the Hanford Site, Washington," Environmental Science and Technology, vol. 39, pp. 3563-3570, 2005.

[9] W. Katharina, H. Christine, and S. Erwin, "Groundwater nitrate contamination: factors and indicators," Journal of Environmental Management, vol. 111, pp. 178-186, 2012.

[10] G. Gabriel, C. Monika, and C. James-R., "An ecologic study of nitrate in Municipal drinking water and cancer incidence in Trnava District, Slovakia," Environmental Research, vol. 88, pp. 182-187, 2002.

[11] Guidelines for Drinking Water Quality, 3rd ed., WHO (World Health Organization), 2008.

[12] J. Y. Cheong, S. Y. Hamm, and J. H. Lee, "Groundwater nitrate contamination and risk assessment in an agricultural area, South Korea," Environmental Earth Sciences, vol. 66, pp. 1127-1136, 2012.

[13] F. M. Pang, W. W. Liang, and M. F. Qiao, "Identification of nitrate source in groundwater using dual isotope $\left(\delta^{15} \mathrm{~N}\right.$ and $\left.\delta^{18} \mathrm{O}\right)$ methods," Agro-Environmental and Development, vol. 4, pp. 64-69, 2011.

[14] C. Abad, S. Mathieu, and R. Cornelia, "Origin of nitrogen in reforested lignite-rich mine soils revealed by stable isotope analysis," Environmental Science and Technology, vol. 42, pp. 2787-2792, 2008.

[15] P. Macro, F. Domenico, and A. Ramon, "Application of isotopic and geochemical tools for the evaluation of nitrogen cycling in an agriculture basin, the Fucino Plain, Central Italy," Journal of Hydrology, vol. 372, pp. 124-135, 2009.

[16] A. Andrade, and T. Y. Stigter, "Multi-method assessment of nitrate and pesticide contamination in shallow alluvial groundwater as a function of hydrogeological setting and land use," Agricultural Water Management, vol. 96, pp. 1751-1765, 2009.

[17] D. W. Hall and D. W. Risser, "Effects of agricultural nutrient management on nitrogen fate and transport in Lanaster County Pennsylvania," Journal of the American Water Resources Association, vol. 29, pp. 55-76, 1993.

[18] M. Chandra and B. Mandal, "Nitrate enrichment in groundwater from long-term intensive agriculture: It's mechanistic pathways and prediction through modeling," Environmental Science and Technology, vol. 43, pp. 5837-5843, 2009.

[19] C. Kendall and J. J. McDonnell, Isotope Tracers in Catchment Hydrology, 1st ed., Amsterdam: Elsevier, 1998, pp. 519-576.

[20] J. Fatima-Zahra, G. EI, and S. Mathieu, "Using $\delta^{15} \mathrm{~N}$ and $\delta^{18} \mathrm{O}$ values to identify sources of nitrate in karstic springs in the Paris basin (France)," Applied Geochemistry, vol. 35, pp. 230-243, 2013.

[21] C. Y. Zhang, Z. Wang, and X. D. Cheng, "Studies of nitrogen isotopes in sources of nitrate pollution in groundwater beneath the city of Zhangye," Journal of Arid Land Resources and Environment, vol. 18, pp. 79-85, 2004

[22] B. Deutsch, M. Mewes, and I. Liskow, "Quantification of diffuse nitrate inputs into small river system using stable isotopes of oxygen and nitrogen in nitrate," Organic Geochemistry, vol.37, pp. 1333-1342, 2006.

[23] M. Voss, B. Deutsch, and R. Elmgren, "Sources identification of nitrate by means of isotopic tracers in the Baltic Sea catchments," Biogeosciences, vol. 3, pp. 663-676, 2006.

[24] J. W. Moore and B. X. Semmens, "Incorporating uncertainty and prior information into stable isotope mixing models," Ecology Letters, vol. 11 , pp. 470-480, 2008

[25] D. M. Xue, J. Botte, and D. B. Bernard, "Present limitations and future prospects of stable isotope methods for nitrate source identification in surface and groundwater," Water Research, vol. 43, pp. 1159-1170, 2009.

[26] D. L. Phillips and J. W. Gregg, "Source partitioning using stable isotopes: Coping with too many sources," Oecologia, vol. 41, pp. 996-1008, 2003.

[27] S. A. Hall, A. P. Hall, and T. L. Rogers, "A new approach to the solution of the linear mixing model for a single isotope: Application to

the case of an opportunistic predator," Oecologia, vol. 143, pp. 143-147, 2005.

[28] P. C. Andrew and A. Jackson. (October 2008). SIAR: Stable isotope analysis. [Online]. Available: http://cran.r-project.org/web/packages/siar/index. html

[29] P. C. Andrew, L. Richard, and B. Stuart, "Source partitioning using stable isotopes: coping with too much varition," PLOS ONE, vol. 5, pp $1-5,2010$.

[30] D. M. Xue, D. B. Bernard, and V. C. Oswald, "Use of a bayesian isotope mixing model to estimate proportional contributions of multiple nitrate sources in surface water," Environmental Pollution, vol. 161, pp. 43-49, 2012.

[31] T. D. Marion, M. E. Emily, and J. B. Daniel, "Quantification of nitrate sources to an urban stream using dual nitrate isotopes," Environmental Science and Technology, vol. 48, pp. 10580-10587, 2014.

[32] C. Y. Zhang et al., "The application of visual modflow to the simulation of groundwater nitrate contamination in Shijiazhuang," Acta Geoscientica Sinica, vol. 28, pp. 561-566, 2007. (in Chinese)

[33] L. A. Schipper and V. M. Vojvodic, "Five years of nitrate removal, denitrification and carbon dynamics in a denitrification wall," Water Research, vol. 35, pp. 3473-3477, 2001

[34] K. E. Garrett and A. L. Hudson, "Large-scale application of in situ remediation to remove nitrate from groundwater," Federal Facilities Environmental Journal, vol. 16, pp. 97-108, 2005.

[35] B. Deutsch, B. Mewes, and I. Liskow, "Quantification of diffuse nitrate inputs into a small river system using stable isotopes of oxygen and nitrogen in nitrate," Organic Geochemistry, vol. 37, pp $1333-1342,2006$

[36] A. Johannsen, K. Dähnke, and K. Emeis, "Isotopic composition of nitrate in five German rivers discharging into the North Sea," Organic Geochemistry, vol. 39, pp. 1678-1689, 2008.

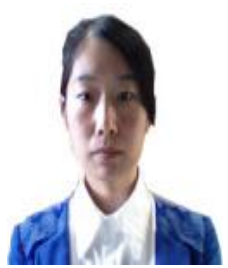

Wen Xu was born in Hubei, China on July 1, 1989. She obtained a bachelor degree in groundwater science and engineering from the School of Environmental Science, China University of Geosciences (Wuhan) in 2011. She went further study in her alma mater, and the main research fields were groundwater pollution and protection, environmental isotope tracing. In 2014, she graduated with a master's degree in groundwater science and engineering. Now, she is a $\mathrm{PhD}$ student at the School of Environment, Beijing Normal University, China. Her main research interest is the monitoring and management of reactive nitrogen in agriculture soils and groundwater environment.

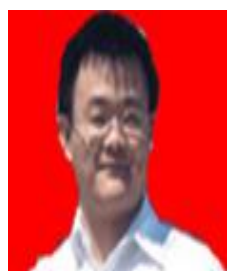

development.

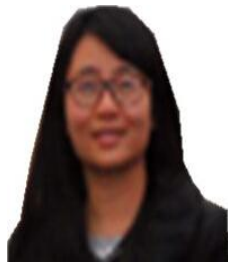

and sustainable development.

Yanpeng Cai was born in Sichuan, China. He obtained a Ph.D. degree in environmental systems engineering at the University of Regina in Canada. He is now a professor at the School of Environment, Beijing Normal University, China. His research interests cover integrated non-point source pollution management, environmental decision-making under uncertainty, ecological remediation, and sustainable

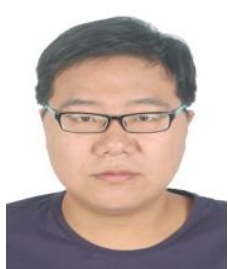

Yan Xu was born in Shaanxi, China on January 12 1989. He obtained a master degree of municipal engineering from Xi' an University of Architecture and Technology, Xi'an, China in 2014, and the main research fields were the municipal engineering and the source water treatment engineering. Now, he is studying in the Beijing Normal University, Beijing, China for earning his Ph.D. degree in environmental science form School of environment, Beijing, China. His main research interest is the simulation and management of ecological process under the condition of coastal reclamation. Currently, he has published three papers about environmental simulation in domestic and international journals. 